\title{
Study on the Influence Factors of the Success Rate in Electric Information Acquisition System
}

\author{
Zhengye Wang ${ }^{1,3, a}$, Gangjun Gong ${ }^{1,3, b}$, Pingfei Zhu ${ }^{2, c}$, Jing Zhao ${ }^{2, d}$ and \\ Yafeng Wen ${ }^{1, \mathrm{e}}$
}

${ }^{1}$ North China Electric Power University, No.2, Beinong Road, Huilongguan Town, Changping District, Beijing, China

${ }^{2}$ Beijing China-power Information Technology Co. Ltd, No.15, Xiaoying East Road, Haidian District, Beijing, China

${ }^{3}$ Beijing Engineering Research Center of Energy Electric Power Information Security, No.2, Beinong Road, Huilongguan Town, Changping District, Beijing, China

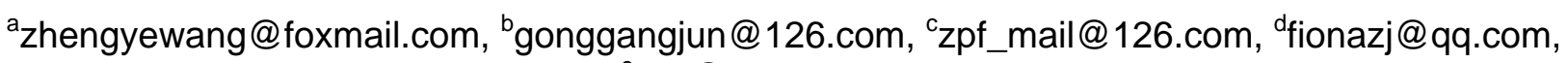
ewyf@ncepu.edu.cn

Keywords: Acquisition success rate, Maintenance, Reading strategies

Abstract. The electric information acquisition system is a powerful support for smart grid by collecting information from users, and the acquisition success rate is required more than $99 \%$. However, the stable operation of the system depends on the equipment performance, technology selection, mechanism, maintenance and so on. This paper is based on the current situation of the system in a province, analyzed the influence factors like management, the master station, communication and equipment, then the feasible suggestions are given according to the main factors.

\section{Introduction}

Electric information acquisition system is a collection, processing and monitoring system for power users, it is an important part of the intelligent power grid, which provides data support for the business for other service systems. Acquisition success rate is an important index of performance of the system, Reference [1] analyzed the communication factors, master station to concentrator, concentrator to intelligent meter and concentrator to acquisition terminals; Reference [2-4] respectively analyzed three factors, they are human factors, environmental factors and system equipment factors.

\section{The current situation of a province}

The electric information acquisition system in one province was launched in 2011, has been operated for more than three years but the acquisition success rate has not reached. Information in this paper is obtained by data collection, questionnaire survey, field investigation and seminars. As shown in table 1 and table 2, the acquisition success rates from four cities (namely A, B, C and D) are collection, the main problems from city reactions are analyzed. After the two tables, the master file, the local channel and remote access and the operation conditions are described.

Table 1: the acquisition success rates

\begin{tabular}{|c|c|}
\hline City & Success rate \\
\hline A & $99.3 \%$ \\
\hline B & $97 \%$ \\
\hline C & $96 \%$ \\
\hline D & $98.5 \%$ \\
\hline
\end{tabular}


Table 2: the main problems from city reactions

\begin{tabular}{|l|c|}
\hline \multicolumn{1}{|c|}{ Main problems } & $\begin{array}{c}\text { The number of cities with } \\
\text { this problem }\end{array}$ \\
\hline Weak and blind area of GPRS signal & 7 \\
\hline Some SIM cards are thin & 4 \\
\hline $\begin{array}{l}\text { Extensive calls debugging by network } \\
\text { updating }\end{array}$ & 3 \\
\hline SIM card in file management & 4 \\
\hline Communication by different weather & 3 \\
\hline Software version of the terminal & 3 \\
\hline Module damaged by lighting & 4 \\
\hline Interoperability of different manufacturers & 2 \\
\hline Device clock disabled & 2 \\
\hline Terminal restart frequently & 2 \\
\hline Manufacturers exit the market & 1 \\
\hline
\end{tabular}

The city A and D have a higher success rate in the provincial company rank. These cities promote the collection work were late, and there were less installation quantity. Their leaders attached great importance to the acquisition working, strictly control the whole file, from installation, operation to maintenance. Besides, they set a high level of assessment indicator for the company which operates and maintains the system. However, some carrier modules are not stable enough, some concentrators are out of the market, and there is something wrong with GPRS signal. These would affect the success rate of acquisition.

The city $\mathrm{B}$ and $\mathrm{C}$ have a lower success rate in the provincial company rank. These cities have low installation coverage, and some new buildings without people. There are non-smart meters in the system. The GPRS signal is not stable in the urban area. Besides, they set a high level of assessment indicator for the company which operates and maintains the system. All the reasons would affect the success rate.

\section{Influence factors}

The success rate is an important technological index of the system. However, many factors would cause troubles like abnormal meter reading, date cannot transmit to the master station, and then the success rate would reduce. Based on the research, factors would be divided into four aspects, respectively management, master station, communication technology and terminal equipment.

Management. Management includes the operation and maintenance, assessment indicators, user advocacy, communication with supplier, etc. As shown in table 3.

\section{Table 3: management factors}

\begin{tabular}{|c|l|}
\hline operation and maintenance & $\begin{array}{l}\text { Some companies maintain by themselves, but they are lack of } \\
\text { technological ability to solve problems; some maintain by } \\
\text { others, but they change frequently. }\end{array}$ \\
\hline assessment indicators & $\begin{array}{l}\text { All the companies would set assessment indicators to } \\
\text { maintenance units. The higher they set, the better they do. }\end{array}$ \\
\hline user advocacy & $\begin{array}{l}\text { The acquisition system promoted is not enough, some users } \\
\text { cannot fully understand, they would do something wrong to } \\
\text { effect the rate. }\end{array}$ \\
\hline communication with supplier & $\begin{array}{l}\text { The communication with supplier will affect the time of net } \\
\text { upgrading, channel optimization and so on. }\end{array}$ \\
\hline
\end{tabular}

Master station. Master station is the center of the collection system, which is very important. The main influence factors are reading strategy, automatic reading task generation, archives management and itself monitoring. As shown in table 4. 
Table 4: master station factors

\begin{tabular}{|c|l|}
\hline reading strategy & $\begin{array}{l}\text { Frozen command from master station everyday would waster } \\
\text { channel resource, because they do not judge it success or } \\
\text { not. }\end{array}$ \\
\hline task generation & $\begin{array}{l}\text { Some tasks need to manually generate. When people on duty } \\
\text { are less, the task may be generated lately. }\end{array}$ \\
\hline archives management & $\begin{array}{l}\text { User profiles in acquisition system and marketing system are } \\
\text { different, the information of equipment is incomplete, and no } \\
\text { SIM cards information in master station. }\end{array}$ \\
\hline itself monitoring & $\begin{array}{l}\text { The monitoring and warning system of the master station, } \\
\text { such as to hardware, software, database, storage, } \\
\text { communication and so on, is not perfect. }\end{array}$ \\
\hline
\end{tabular}

Communication technological. In this aspect, it is mainly from two aspects: low voltage networking technology and thunderstorm weather. As shown in table 5.

Table 5: Communication factors

\begin{tabular}{|c|l|}
\hline networking technology & $\begin{array}{l}\text { This technology is different in different manufacturers, and } \\
\text { the difference is relatively large. The reading time, reading } \\
\text { stability would affect success rate. }\end{array}$ \\
\hline thunderstorm weather & $\begin{array}{l}\text { In some areas, the thunderstorm weather is more, when the } \\
\text { preventive measures are not perfect, the equipment would be } \\
\text { damaged, affecting the success tare. }\end{array}$ \\
\hline
\end{tabular}

Terminal equipment. Equipment quality and legacy issues are the main two issues that should be taken into consideration. As shown in table 6.

Table 6: Equipment factors

\begin{tabular}{|c|l|}
\hline equipment quality & $\begin{array}{l}\text { Special transformer terminal is generally reliable, has few } \\
\text { problems, however, the troubles with concentrators are more . }\end{array}$ \\
\hline legacy issues & $\begin{array}{l}\text { Because of some terminal companies were out of market, } \\
\text { there are no after-sale services, it is harmful to maintain, } \\
\text { affecting the success rate. }\end{array}$ \\
\hline
\end{tabular}

\section{Related suggestion}

According to the survey, the application of low voltage carrier communication is basically maturely, the success rate of each factory terminal can reach to $98 \%$. Acquisition success rate can be further enhanced after optimization and combination with actual situation. In order to solve the low success rate in some cities, some improvement measures need to take into consideration.

\section{Management.}

Define boundary. Define the scope of the system according to the main task, and then focus on acquisition, operation and maintenance, as far as possible to reduce other works.

Monitor working. The city power supply company should set up a monitoring center, responsible acquisition, operation, maintenance and communication with suppliers.

Improve maintenance. Set up reasonable indicators for units, strengthen business skills, put forward incentives and punishment measures.

Strengthen cooperation. Strengthen cooperation with the operators and users, the system would work better with their cooperation.

\section{Master station.}

Define reading strategy. Determine reasonable reading time and reading order, avoid the time of the network updating.

Optimize task generation. Automatic command instead of manually generate when reading fails, to improve lower rate at weekends. 
Upgrade hardware configuration. Use advanced technologies, like distributed cloud computing, data partition technology, memory storage and other technologies to solve the problems of construction and function.

File management. Start from master station, check and correct the previous files, establish file strictly for new terminals.

\section{Communication technological.}

Remote communication. GPRS/CDMA's two mode communication module is used to replace the single communication technology, to improve communication reliability.

Local communication. Use narrow carrier and micro power wireless communication which has high reliability and high rate, to support date acquisition and remote control.

\section{Terminal equipment.}

Equipment quality. Change equipment which worked too long, upgrade those equipment which cannot meet the newest statute.

Equipment fit. The combination between different manufacturers is needed to test, like reading time, the success rate.

\section{Summary}

The use of electric information acquisition system adopts automatic meter reading instead of manual meter reading, which ensures the data's real-time and accuracy, greatly improve the efficiency of electric power system. But the success rate of collection is not high enough, this paper analyzes the actual situation of the survey, determine the factors that affect the success rate, and gives the corresponding measures.

\section{Acknowledgements}

The work was supported by a general program from the Basic Science Research Fund of Central Universities (No.JB2014048).

\section{References}

[1] Jianwei BAI, Huiyong LI, Jinyong NIU: Shanxi Electric Power, 2013, (6): 42-44.

[2] Genshui HONG: KEJI and QIYE, 2013, (20): 159-159.

[3] Lu XIONG: Management \& Technology of SME, 2015, (8): 301-302.

[4] ZHANG Lei: Super Science, 2015, (12): 52-53. 